\title{
A arqueologia da arquitetura: um modo de entender e conservar edifícios históricos
}

Regina A.Tirello*

\section{RESUMO}

Este artigo apresenta sistemáticas de estudo e registro de resultados de sondagens de superfície que, combinadas a análises científicas e documentos, são empregadas para reconhecimento e avaliação de edifícios históricos de cronologia construtiva complexa, inserindo-se nas premissas disciplinares da Arqueologia da Arquitetura.

Trata-se de pesquisas de natureza arqueométrica e estratigráfica que vêm sendo desenvolvidas há alguns anos no âmbito do programa "Conservação e Restauração de Bens Arquitetônicos e Integrados" do Centro de Preservação Cultural da Universidade de São Paulo (CPC-USP), com a participação de pesquisadores de diversas áreas e estudantes.

Essa categoria de estudo fornece sólido conjunto de dados físicos indiciais sobre os objetos que, para além das datações referenciais, conduz a importantes conhecimentos sobre materiais, técnicas e procedimentos construtivos e artísticos usados no passado. Ocorre que as sistemáticas estratigráficas geram dados aparentemente heterogêneos, de difícil interpretação para profissionais pouco habituados com práticas prospectivas.

Apresentando como estudo de caso a Casa de Dona Yayá, propõe-se aqui a definição e emprego de indicadores temporais, cuja leitura entrecruzada possa facultar o entendimento da historia construtiva de uma arquitetura estudada. Para explicitar as especificidades e perímetros de cada unidade estratigráfica virtual, utilizamos recursos da computação para delinear uma sistemática de síntese gráfica apoiada na tridimensionalidade, considerada mais adequada à representação arquitetônica.

Palavras-chaves: Preservação arquitetônica. Arqueologia da arquitetura. Casa de Dona Yayá. 


\title{
Architecture archeology: a way to understand and preserve historical buildings.
}

\begin{abstract}
This article presents a study system and register results of surface exploration which, combined with documents and scientific analysis, are employed to acknowledge and assess historical buildings of complex building chronology, as part of the basic postulates of the Architecture Archeology as a discipline. It is about archaeometric and stratigraphic researches that have been carried out for some years within the framework of the program "Integrated Architectural Assets Conservation and Restoration" of the University of São Paulo Cultural Preservation Center (CPC-USP), with the participation of researchers and students from different areas.
\end{abstract}

This study category provides a solid set of indicative physical data about objects which, beyond their dating reference, lead to important understanding about building and artistic material, techniques and procedures used in the past. What happens is that stratigraphic systematic produces data which are apparently heterogeneous and hard to interpret for professionals unaccustomed to prospective practices.

This article presents a case study of Casa de Dona Yayá (Yayá's House), in São Paulo, and aims to define and employ time indicators which, intertwined, can shed light upon the building history of a studied architecture. To highlight specificities and boundaries of every stratigraphic virtual unit coming from such indicators, we resort to computer technology to portray a system of graphic synthesis supported by tridimensionality, considered more adequate to architectonic representation.

Key words: Architecture preservation, architecture archaeology, Casa de Dona Yayá.

\section{A matéria é o suporte do tempo}


A arqueologia da arquitetura é disciplina nova que vem se afirmando internacionalmente, em especial na Espanha e Itália, com estudos aplicados à arquitetura medieval. Seus instrumentos principais de pesquisa estruturam-se na análise da estratigrafia murária (explorada em muitas direções) e exames microanalíticos, efetivamente pouco destrutivos ao corpo dos edifícios. Essa sistemática possibilita avaliação de seqüências plurais do objeto, que em muito ultrapassam o simples reconhecimento de tipologias técnicas e construtivas para viabilizar a leitura e interpretação, também, das funções e significados dos materiais e formas identificados nos edifícios antigos. (TIRELLO, 2006, p. 1)

Neste sentido, os resultados advindos de pesquisas desta natureza, mais que ao embasamento de projetos de restauração e conservação, prestam-se ao aprofundamento de estudos sobre a "cultura material" dos povos, de interesse para a historia da arquitetura e das artes, a arqueologia histórica, a etnologia, a antropologia, e outras disciplinas correlatas.

A Casa de Dona Yayá é um dos edifícios de valor histórico-cultural pertencentes à Universidade de São Paulo no qual se desenvolveram pesquisas pioneiras, voltadas ao estabelecimento de metodologias de investigação e registro de cronologias arquitetônicas complexas, por meio da aplicação de sistemas estratigráficos.

Já em 1989, quando dos estudos iniciais visando à preservação da casa - que levaram à identificação material do núcleo antigo do edifício, construído no final da década de 1880, e de todas as suas ampliações subseqüentes (TIRELLO, 2001) - o propósito era o de aprofundar pesquisas sobre técnicas construtivas e ornamentais tradicionais e oferecê-las à consulta pública. A riqueza de informações a respeito do saper fare e materiais antigos que este edifício engendrava, requeria e possibilitava estudos em muitas direções, principalmente na do conhecimento dos modos de construir e morar do final do século XIX na cidade de São Paulo.

Assim, para além do interesse por técnicas de restauro, a particular vertente arqueológica do trabalho de investigação a ser então realizado nessa casa impôs-se pela nossa linha conceitual preservacionista: a restauração e a conservação dos monumentos demandam estudos cada vez mais dirigidos às particularidades dos 
interesses científicos que orientam suas ações principais: o conhecimento dos materiais constitutivos como dado histórico informativo, e a ampliação da base técnica para intervenções de conservação e restauro de bens culturais. Antes de restaurar - e hoje, mais do que nunca - é preciso conhecer o objeto para bem conservá-lo.

Com essas premissas, o hoje intitulado programa "Conservação e Restauração dos Bens Arquitetônicos e Integrados" do CPC-USP (1), sob minha responsabilidade, desenvolve já há mais de uma década estudos pertinentes à arqueologia da arquitetura dos quais participam estudantes-bolsistas e pesquisadores de diversos institutos científicos da USP, tais como Instituto de Pesquisas Tecnológicas (IPT), Instituto de Química (IQ), Escola Politécnica (Poli), Instituto de Geociências (IGc), entre outros.

O reconhecimento de cronologias arquitetônicas requer avaliações múltiplas e imbricadas. No aspecto da análise histórica, contam os documentos textuais e iconográficos (sempre raros, escassos), como também o entendimento das alterações estruturais, morfológicas, programáticas e ambientais havidas ao longo da vida dos edifícios, e que nem sempre são tão evidentes e lógicas quanto se desejaria. Se as lacunas documentais são uma constância - bem o sabem os profissionais que atuam na área - grande utilidade e valia adquire o testemunho dado pelos próprios materiais constitutivos de um edifício estudado.

A matéria é, por excelência, o suporte do tempo. Resta a nós interpretá-la corretamente.

Uma das categorias de exame que temos adotado, com resultados positivos, para avaliação da história material dos edifícios antigos, são as sondagens arqueológicas de superfícies.

Trata-se de um método de estudo de natureza estratigráfica que integra instâncias históricas e materiais de análise do objeto: na chave disciplinar da "arqueologia da arquitetura". Além da Vila Penteado (TIRELLO, 2002) e a Casa de Dona Yayá (imóveis pertencentes a USP) - onde essa metodologia de leituras materiais 
entrecruzadas foi desenvolvida e vem sendo aperfeiçoada -, na última década tevese a oportunidade de aplicá-la, com bons resultados, em vários edifícios paulistas de épocas e tipologias diferenciadas, visando ao reconhecimento primordial das tantas etapas de integridade física e ornamental que Ihes são peculiares. (2)

Além de sondagens prospectivas, adota-se nesse tipo de estudo exames laboratoriais para distinções elementares dos materiais constituintes que integram uma construção. Mas, cumpre destacar, esses exames, sozinhos, não bastam para esclarecer sobre todas as transformações físicas havidas em um objeto ao longo de sua vida. As análises físicas ou químicas só se validam se seus resultados forem cotejados com outros dados relacionados à história plena dos edifícios estudados. Para que serve conhecer o traço de uma argamassa (de amostra recolhida de um ponto qualquer, de uma parede qualquer) sem hipóteses investigativas que o justifique? Fazer prospecções para reconhecer potenciais "cores originais" (original em relação a quê? a quando?) de ambientes ou fachadas de edifícios antigos? É oportuno refletir um pouco sobre essa questão.

A arqueologia da arquitetura é viabilizada pela confluência de métodos provenientes de diferentes áreas do conhecimento requerendo, em conseqüência, a paciente construção de parcerias profissionais e acadêmicas que, no Brasil, por mais que se tenha avançado, nesse sentido, nas duas últimas décadas, ainda continuam difíceis de se efetivar.

$\mathrm{Na}$ busca, por vezes equivocada, da propalada "cientificidade internacional" para procedimentos operativos brasileiros, nota-se que ainda persistem antigos paradoxos. Por um lado existe a tendência à excessiva mitificação das análises científicas, valendo também o seu oposto que é creditar unicamente a documentos escritos, velhas fotografias e desenhos o conhecimento das alterações de um edifício. Mas afinal, que tipo de estudo, de exame, de análise nos possibilitaria formular diretrizes para corretamente propor iniciativas de intervenção e/ou proteção de um bem cultural?

Giulio Carlo Argan adverte sobre os riscos de certos exageros: 
O perigo não é o da especialização enquanto pesquisa setorial consciente do próprio limite; o perigo é o do cientismo, como negação implícita da cientificidade da história e instauração da verificação no lugar da prova, da notícia no lugar do problema, do enunciado no lugar do discurso. O perigo, enfim, é que, em vez de renovar e estender o método histórico, se "desistorize" o método do estudo da arte e que, por fim, mesmo neste campo, uma linguagem tecnológica substitua a linguagem histórica. (ARGAN, 1995, p.22)

Há de se balizar os dados "objetivos", resultantes das análises científicas, com os dados da história das técnicas e das artes, sempre. É um equivoco conferir somente às ciências aplicadas o papel deflagrador de um roteiro de questões a serem investigadas, quando a vertente principal, na área da conservação e do restauro da arquitetura e das artes, costuma ser a do reconhecimento dos fazeres técnicos não documentados. Nesse sentido, é preciso ter em vista que as análises científicas e laboratoriais não são estruturas autônomas de pesquisa, mas complementares à verificação de certas ocorrências históricas do próprio objeto - entendidas como refazimentos, repinturas, mudanças de formas e características originais.

As colaborações interdisciplinares são imprescindíveis, mas - como os próprios conceitos de restauro e conservação ao longo da história - precisam ser constantemente redefinidas em atendimento à mudança dos objetivos: da natureza do ambiente e dos critérios de fruição; do progresso do conhecimento acerca dos mecanismos de ação degenerativa; e do número de informações que os objetos nos fornecem, tanto quanto de sua utilidade para a comunidade.

O estudo de edifícios de interesse histórico-cultural, na perspectiva da arqueologia da arquitetura, mais que instrumentalizar profissionais para seu restauro, deve prestar-se à efetiva ampliação dos conhecimentos sobre os objetos estudados. Define-se e orienta-se por uma série de procedimentos encadeados: leituras de documentos tradicionais, exames empíricos de campo, levantamentos métricos minuciosos, estudos de técnicas construtivas e artístico-artesanais, análises dos sistemas de construção e materiais constitutivos característicos, diagnósticos do tipo de degradação e, também, quando necessários, por exames efetuados com instrumentos de precisão. 
Assim, com as classificações, medidas e representações que aqui apresentamos para reconhecimento e registro da estratigrafia de edifícios antigos - decorrentes de estudos desenvolvidos no CPC-USP - tenciona-se auxiliar na prática profissional, e procura-se, também, ir ao encontro de uma premissa maior: preservar os objetos do passado como possibilidade de fruição presente e documento para o futuro.

\section{Sistemas estratigráficos: a que servem?}

Tem-se como premissa que o reconhecimento da cronologia histórico-arquitetônica de um edifício antigo é etapa imprescindível para o estabelecimento de parâmetros e de critérios norteadores de projetos de caráter preservacionista, sejam eles de conservação, de restauro ou de revitalização.

Os métodos estratigráficos são excelentes para decodificar e ordenar diacronicamente a complexidade construtiva de edifícios históricos, o que os torna instrumentos de grande adequação (porque pouco destrutivos) e utilidade (porque esclarecem ambigüidades construtivas) para a definição de projetos de restauro arquitetônico.

Essas análises diretas geram um conjunto de dados indicativos sobre a "matéria dos edifícios" que, quando correlacionados e orientados por pesquisas histórico-formais e de laboratório, possibilitam o delineamento de seguros indicadores cronológicos. Permitem-nos reconhecer as subtrações e/ou anexações que uma arquitetura sofreu ao longo de sua vida, que quase nunca estão registradas em documentos convencionais.

No entanto, as dificuldades de decodificar e de sintetizar tantas informações entrecruzadas - que as múltiplas categorias de sondagens impostas pelos métodos estratigráficos são capazes de gerar - por vezes obstaculiza a plena utilização dos resultados dessa categoria de pesquisa por parte dos arquitetos, restauradores e outros profissionais da área da preservação.

O trabalho que vimos desenvolvendo, propõe-se ao delineamento de sistemáticas de exposição de resultados de sondagens materiais que se apresentam confusamente a um observador menos habituado às práticas prospectivas. 
No contexto da arqueologia da arquitetura fragmentos minúsculos, texturas e cores diferenciadas podem se constituir em indicadores temporais que, revelando as evidencias do tempo passado, permite-nos leitura interpretativa dos processos construtivos antigos, entre outros aspectos relevantes, tais como morfologias e ambiências constituídas.

Os objetivos gerais dos nossos estudos são:

- Fixar critérios comparativos para analisar, contemporaneamente, indicadores temporais de naturezas diversas;

- Estudar organização gráfica que sintetize as especificidades e perímetros de cada unidade estratigráfica virtual usando-se a tridimensionalidade, considerada mais adequada à representação arquitetônica;

- Facultar, por meio de sínteses gráficas, a compreensão de todas as fases evolutivas dos edifícios antigos como apoio útil para projetos de profissionais que atuam na área de preservação, e que provêm de formações diferenciadas (arquitetos, historiadores, restauradores, arqueólogos, cientistas);

- Colaborar com o processo de informatização de inventários de bens arquitetônicos, avaliando a adequação dos suportes digitais como auxílio útil à documentação crítica de estruturas históricas e, em conseqüência, à fundamentação criteriosa de projetos subsidiários a iniciativas preservacionistas.

\section{Estudos de fonte diretas e indiretas geram indicadores temporais}

Os sistemas de leituras interpretativas de estratigrafias arquitetônicas baseiam-se no estudo combinado das fontes indiretas (as pesquisas histórico-documentais convencionais) e das fontes diretas, relativas às análises dos sistemas construtivos e materiais constitutivos de uma arquitetura.

Esses exames se desenvolvem por meio de: 
- Estudo da estrutura edificada: investiga-se o sistema estrutural, tipo/natureza do material construtivo, técnicas de trabalho, características dimensionais, textura, coloração, acabamento;

- Estudo dos revestimentos: Analisa-se a natureza do material (cargas e agregados) traço, granulometria, compactação, coloração, acabamento superficial;

- Estudos dos ornamentos artísticos: estuda-se a tipologia técnica e material, forma de aplicação, textura, refletância, cor, desenho (quando possível), acabamentos.

A experiência profissional comprova a insuficiência das tabelas descritivas, fotografias e gráficos bidimensionais para estabelecer a correlação efetiva entre as três instâncias de análises citadas. Assim, por considerar a tridimensionalidade mais adequada à representação de formas arquitetônicas, estudou-se uma organização gráfica específica para "resumir" as especificidades e perímetros de cada unidade estratigráfica virtual de edifícios antigos.

Nesta sistemática, os dados resultantes das sondagens e outros tipos de exames realizados foram organizados e sistematizados em três categorias de estudo, interdependentes, que chamamos de indicadores temporais. A saber:

Indicador temporal 1: estrutura edificada;

Indicador temporal 2: revestimentos;

Indicador temporal 3: ornamentos artísticos;

Para expor sucintamente os procedimentos que temos adotado para analisar e registrar a estratigrafia material arquitetônica e ambiental de edifícios paulistas, apresenta-se a seguir um estudo de caso.

4 Um estudo de caso e um histórico do método: a Casa de Dona Yayá 
A Casa de Dona Yayá (atual Centro de Preservação Cultural da USP) que, apesar de já restaurada, os estudos de cronologia foram retomados no âmbito do "Programa Conservação e Restauração de Bens Arquitetônicos e Integrados" do CPC-USP, em 2004, nesta perspectiva de síntese gráfica dos indicadores temporais por meio da computação. (www.usp.br/cpc)

Sobre esta casa não havia qualquer informação documental e iconográfica a respeito das alterações ocorridas ao longo do tempo. O que se via era uma fachada com data de 1902, bastante descaracterizada por anexo construído em 1950. Por outro lado, os documentos de compra e venda do edifício, organizados na ocasião da pesquisa histórica, indicavam que, no lugar da casa que conhecemos, uma outra casa, anterior a 1888 , teria sido construída. Se correta a indicação documental, a Casa de Dona Yayá poderia ter em seu núcleo a primeira construção de tijolos da Bela Vista, um bairro popular que se formou na cidade de São Paulo no final do século XIX. (TIRELLO, 2001)

Para reconhecer e distinguir fisicamente esse suposto núcleo originário, do restante da construção, seria necessário criar uma leitura sistemática, que propiciasse "datações relativas referenciais" dos materiais presentes/sobrepostos/justapostos, para que a cronologia histórico-arquitetônica da casa se evidenciasse. Com esse objetivo analisaram-se, simultânea e comparativamente, indicadores temporais de diversas naturezas. A saber:

\section{Indicador temporal 1: exame da estrutura edificada}

Para estabelecer este indicador tomaram-se como referência os seguintes estudos:

- Estudos histórico-documentais: documentos escritos; plantas cadastrais; análises das mudanças de programa de uso morfologia construtiva; linguagem formal.

- Análises dos indícios construtivos: medições; avaliações dos sistemas e técnicas construtivas presentes; sondagens cromáticas e arquitetônicas; e análises laboratoriais de caracterização. 
O resultado foi o reconhecimento de 4 etapas construtivas, relacionadas a seus proprietários, que resultaram em alterações no seu perímetro, nas características arquitetônicas e ambientais. (www.usp.br/cpc)
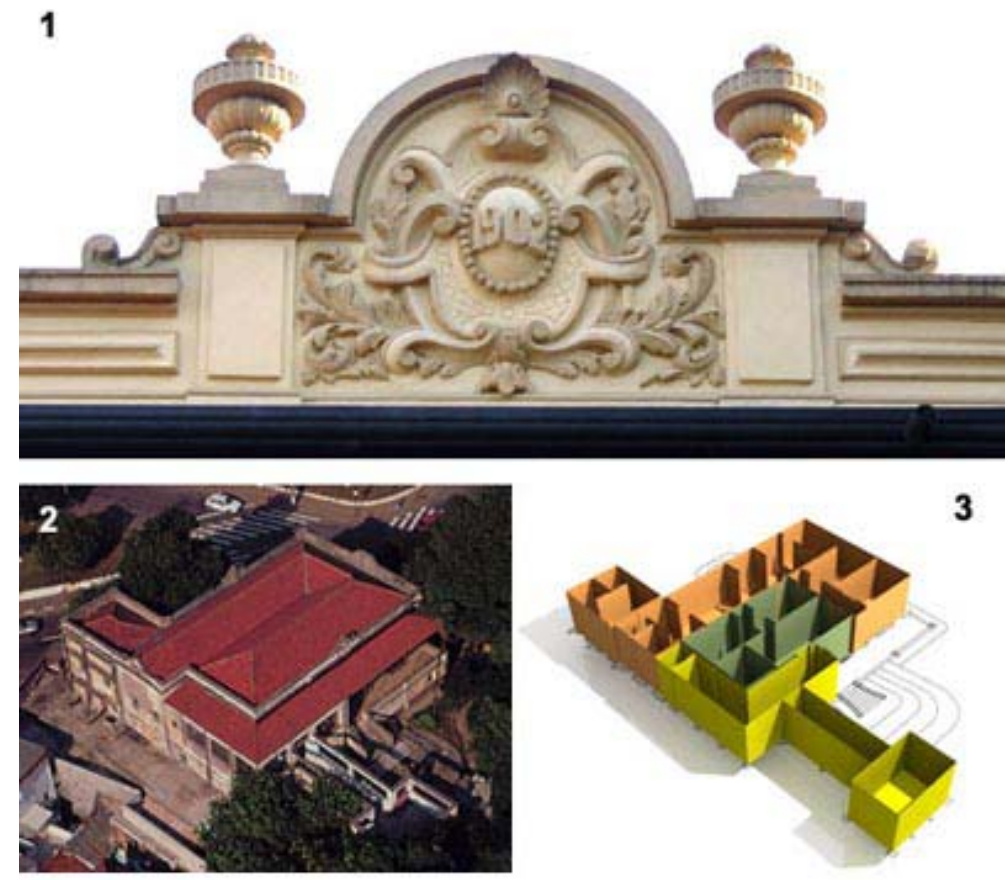

3

FIGURA 01 - Indicador Temporal 1: (1) Fachada da casa com data de 1902, Fonte: Arquivo CPC-USP. (2) Vista área da Casa de D. Yayá antes do restauro. Fotografia: Angela Garcia, 1996. Fonte: Arquivo CPC-USP. (3) Volumetria das quatro etapas construtivas identificadas. Desenho: Pedro Alasmar, 2005. Fonte: Arquivo CPC-USP.

Comprovou-se existir, no centro do edifício atual, um chalé de tijolos anterior à década de 1880; testemunha-o fisicamente as fundações e estruturas localizadas. As aberturas originais dessa pequena construção de quatro cômodos estão sendo investigadas com o auxílio dos indicadores temporais 2 e 3. (ver imagens 3, 5 e 6)

Nesta etapa teve grande importância a análise do sistema construtivo característico da construção identificada como primitiva: das fundações, sistemas construtivos, modo de assentamento dos tijolos, argamassas de rejunte e de revestimento. Estas foram balizas fundamentais para a compreensão da planimetria primitiva e da subseqüente, decorrente das reformas promovidas por diferentes proprietários. 

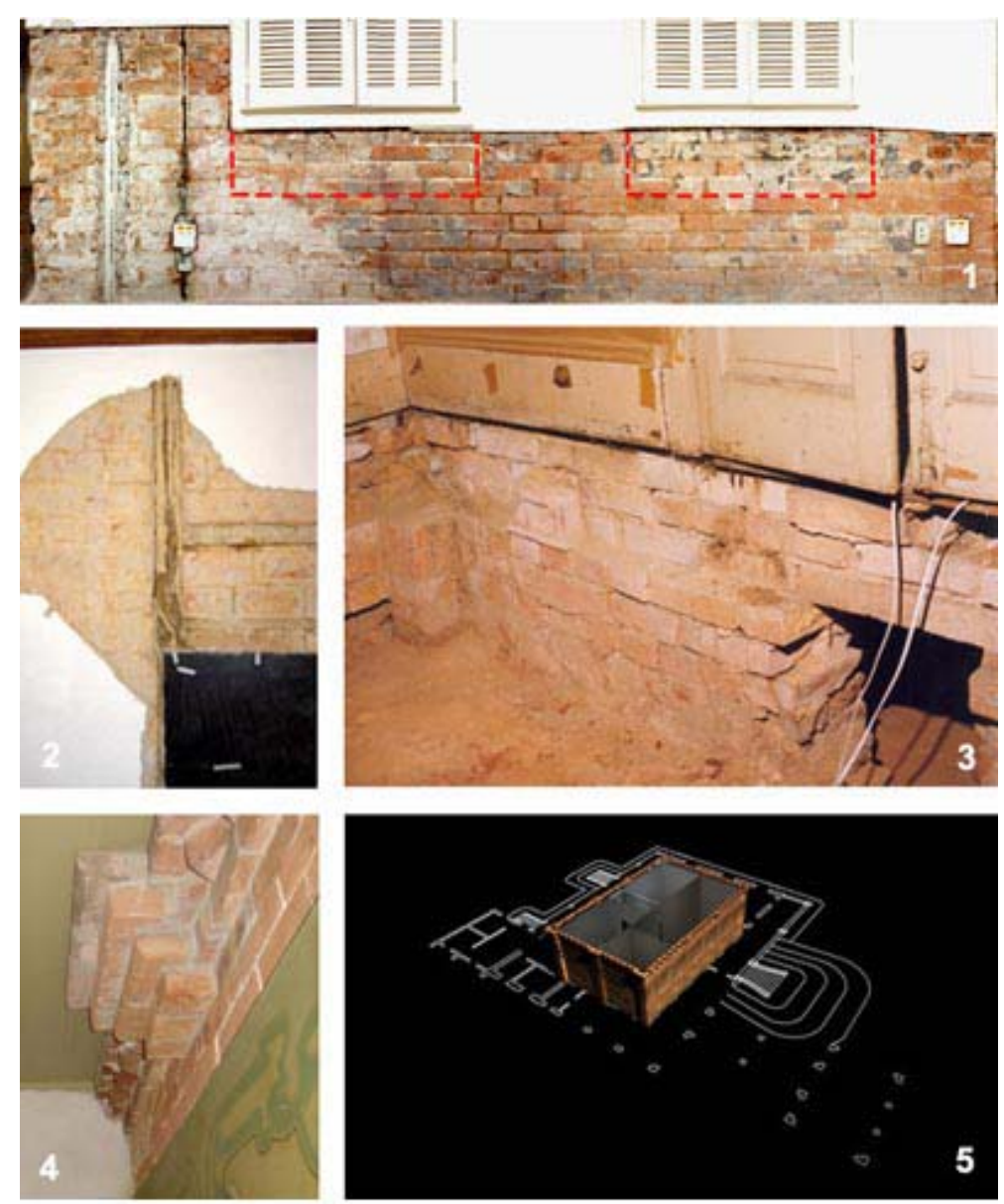

FIGURA 02 - (1) Diferentes argamassas usadas no assentamento dos tijolos evidenciam diminuiçăo do tamanho das janelas nas obras de ampliação do chalé primitiva. (2) Estrutura de madeira das paredes do chalé. (3) e (4) Fundaçōes e cimalha do primeiro chalé de tijolos então escondidos por forros e soalhos. (5) Simulaçð̃o: Volumetria do primeiro chalé de tijolos. Desenho: Pedro Alasmar, 2005. Fonte: Arquivo CPC-USP.

\section{Indicador temporal 2: identificação e análise dos ornamentos artísticos.}

Por meio de sondagem cromática de superfície (que quantifica as possíveis ambientações) e prospecções (que qualificam os modelos ornamentais adotados) pôde-se conhecer diferentes tipologias técnicas e compositivas de pinturas artísticas correspondentes aos muitos ciclos decorativos havidos na casa, num arco de 120 anos. As prospecções superficiais confirmaram plenamente as hipóteses formuladas a respeito das características das reformas havidas, formuladas por meio do indicador temporal 1 (relativo à estrutura edificada).

O resultado global desta etapa foi a identificação de 7 camadas de pinturas sobrepostas em quase todos os cômodos da casa. Delas, as 4 camadas mais antigas foram consideradas de interesse e estudadas sob os seguintes aspectos: a tipologia técnico-material: forma de aplicação, textura, refletância, cor, desenho (quando possível); natureza do acabamento; e modelo artístico. 
Uma reorganização destes dados conduziu à compreensão das peculiaridades de cada fase ornamental da casa (3 ao todo), com seus componentes arquitetônicos e decorações parietais características.
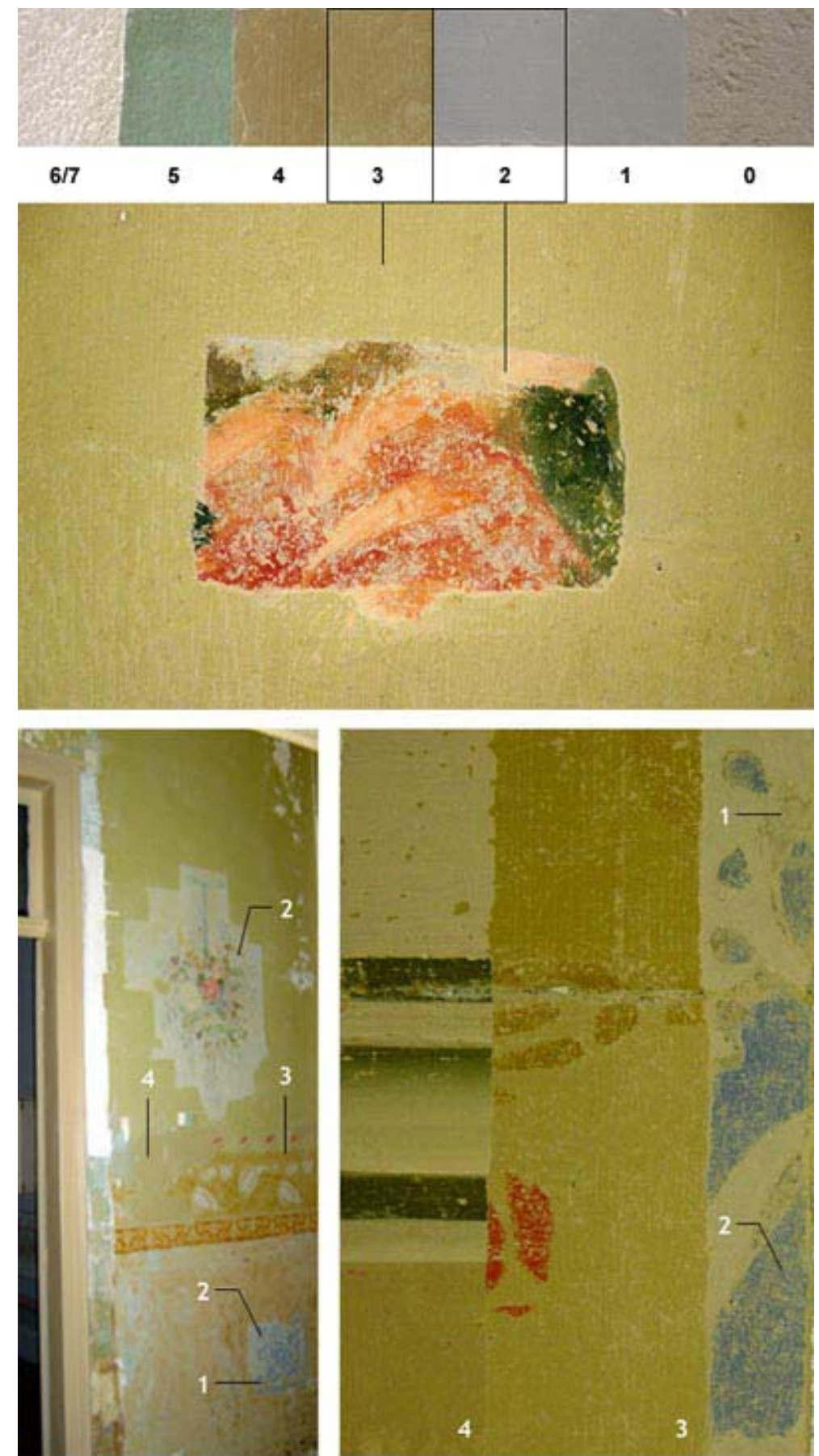

FIGURA 03 - (1) Faixa estratigráfica: Quantifica o numero de camadas de tinta e/ou materiais sobrepostos nas superficies murárias. (2) Área de decapagem. Mostra trecho de duas camadas da faixa estratigráfica (camadas 2 e 3). (3) Vista de parede durante decapagem. (4) Modelos de pinturas artisticas sobrepostas. Ornatos e cores de quatro camadas de pintura executadas em épocas diversas em um mesmo cómodo. O Corredor 1. Fonte: Arquivo CPC-USP. 2004. 
O registro e a organização gráfica desses dados sobre ornamentos parietais antigos (conhecidos apenas parcialmente por meio da pequenas áreas de decapagem) geraram desenhos e tabelas cromáticas que posteriormente foram usadas para compor as primeiras simulações gráficas das paredes de um mesmo cômodo, em diferentes fases decorativas.

O resultado global foi a criação de um banco de dados digital que terminou por subsidiar a realização da maquete eletrônica da Casa de Dona Yayá, que está sendo finalizada para exposição pública.

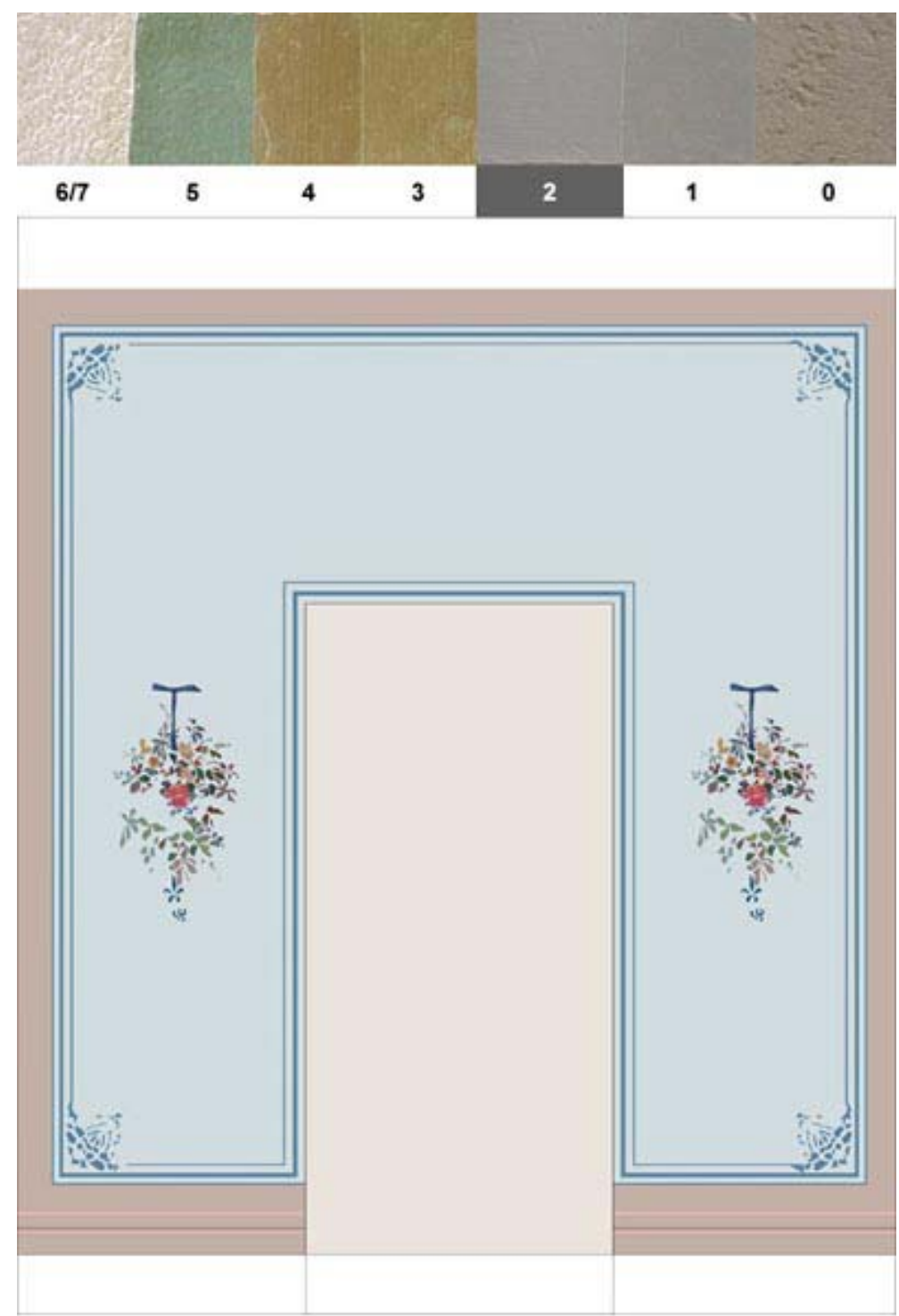

FIGURA 04 - Indicador Temporal 2: Reconstituição gráfica da composição ornamental da Parede $C$ do Corredor 1 relativa ao segundo ciclo ornamental identificado na casa. Desenho: Pedro Alasmar, 2005. Fonte: Arquivo CPC-USP.

Indicador temporal 3: análises dos revestimentos 
Estabelece-se esse indicador por meio de:

\section{a) Exame direto das superfícies:}

Avaliação da integridade física e estrutural da parede em exame, avaliando-se: alterações morfológicas (fissuras, relevos, alterações de prumo), coloração das superfícies, características de compactação das massas, características de imprimação, identificação de alterações naturais e/ou antrópicas.

Nesta instância do trabalho, com exames macroscópicos das superfícies argamassadas, busca-se o reconhecimento das características físicas principais dos materiais sobrepostos e/ou justapostos, anotando-se os resultados em fichas elaboradas para este fim. Somente após essas avaliações basilares é que se procede a seleção e extração de amostras de material de pontos/trechos, considerados relevantes para a pesquisa, para a realização de exames laboratoriais de caracterização.

\section{b) Exames com instrumentos de precisão:}

Para distinção material constitutiva dos substratos, realizam-se: análise quantitativa do agregado e identificação dos componentes associados/grau de cimentação etc; análise granulométrica, análise mineralógica-petrográfica.

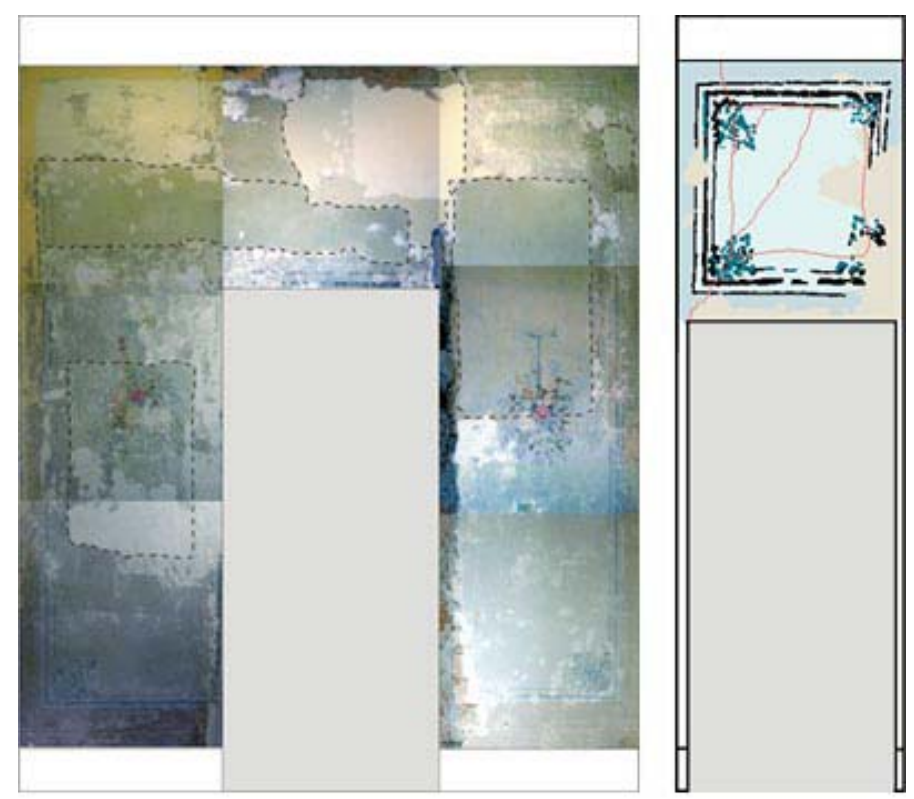

FIGURA 05 - Indicador Temporal 3: À direita, gráfico bidimensional assinalador de camadas de tinta e argamassas analisadas contemporaneamente. Desenho: Pedro Alasmar, 2005. Fonte: Arquivo CPC-USP. A esquerda, registro fotográfico da situação da camada a ser restaurada após remoção das sobrepinturas da Parede $C$ do Corredor 1 , em fevereiro de 2006 , em que se evidenciam as trincas indicativas de diferenças de materiais (vãos pré-existentes) no suporte a investigar com metodos variados. Desenho: Pedro Murilo, 2006. Fonte: Arquivo CPC-USP. 

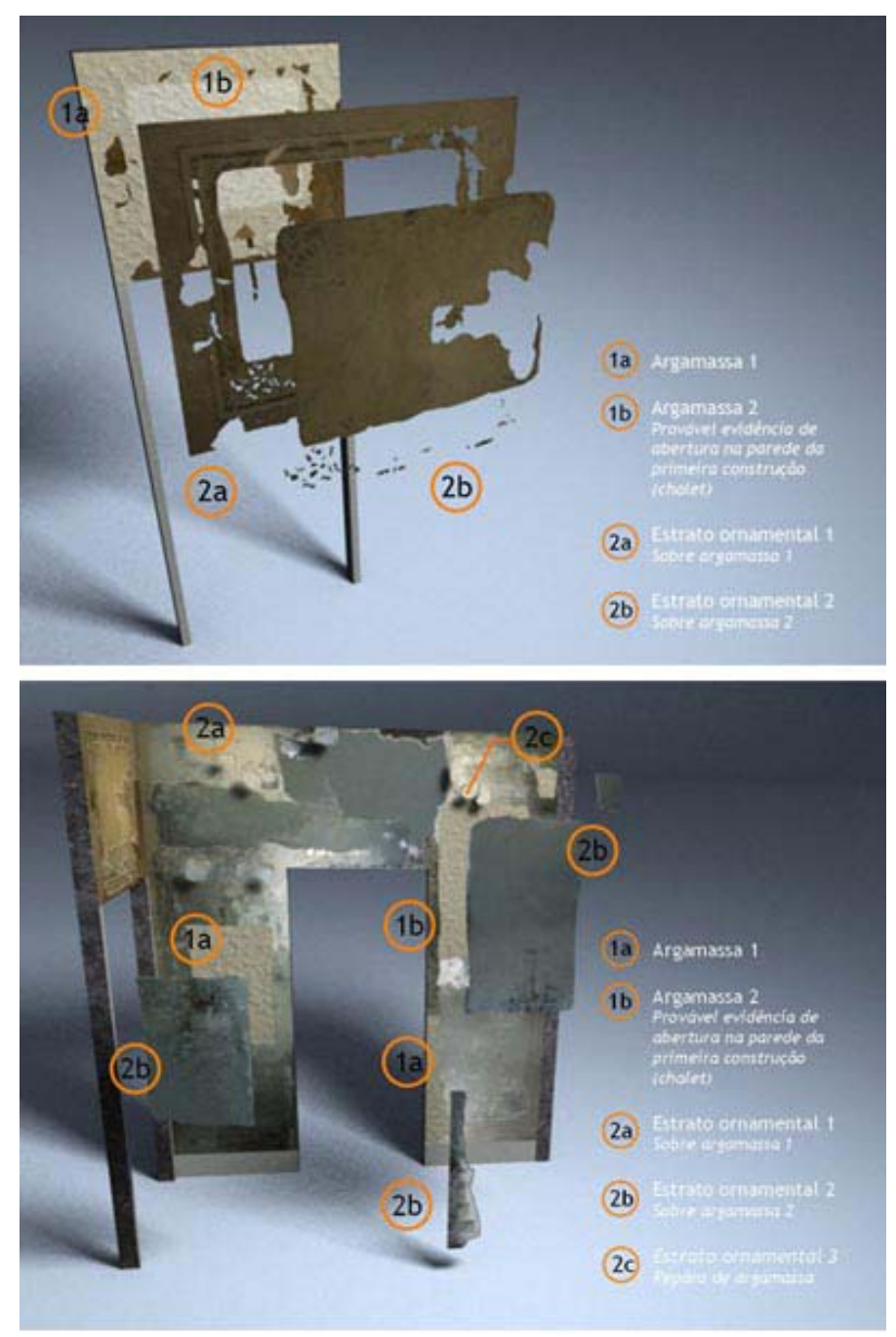

FIGURA 06 - Indicador Temporal 3: Desenhos tridimensionais representando as mesmas sobreposiçōes da figura 05. Desenhos: acima, Pedro Alasmar, 2005; abaixo, Pedro Murilo, 2006. Fonte: Arquivo CPC-USP.

5 As sínteses gráficas: indícios e fragmentos de matéria se organizam em maquete virtual

A partir da interpretação dos materiais artísticos constitutivos originais e agregados, pode-se chegar a 4 diferentes perímetros, volumetrias e ambiências, constituídas ao longo da vida deste edifício, que perfaz 120 anos de história, e que coincide com a história construtiva do próprio bairro em que se insere, o da Bela Vista, na cidade de São Paulo.

Organizando-se as investigações a partir de 3 indicadores temporais adotados para os estudos cronológicos, criou-se um "arquivo tridimensional" de informações sobre a casa. É um banco de dados eletrônico contendo informações sobre modelos e 
sistemas construtivos, arquitetônicos e picturais, usados em diferentes períodos históricos.

Tomando como base o banco de imagens, vem sendo realizada uma maquete animada que permitirá aos visitantes da sede do CPC conhecer a Casa de Dona Yayá em todas suas etapas construtivas, com a volumetria, forma, cores e ornamentações características:

Fase 1: o chalé de tijolos de quatro cômodos (anterior à década de 1880).

Fase 2: A casa de morada burguesa, resultante da primeira ampliação do chalé primitivo, promovida pelo segundo proprietário da casa.

Fase 3: A casa de morada sofre nova remodelação interior e exterior e ganha elementos "neoclássicos", em consonância com o repertório eclético então em voga.

Fase 4: A casa de habitação transforma-se em casa de saúde privada para abrigar Dona Yayá. 

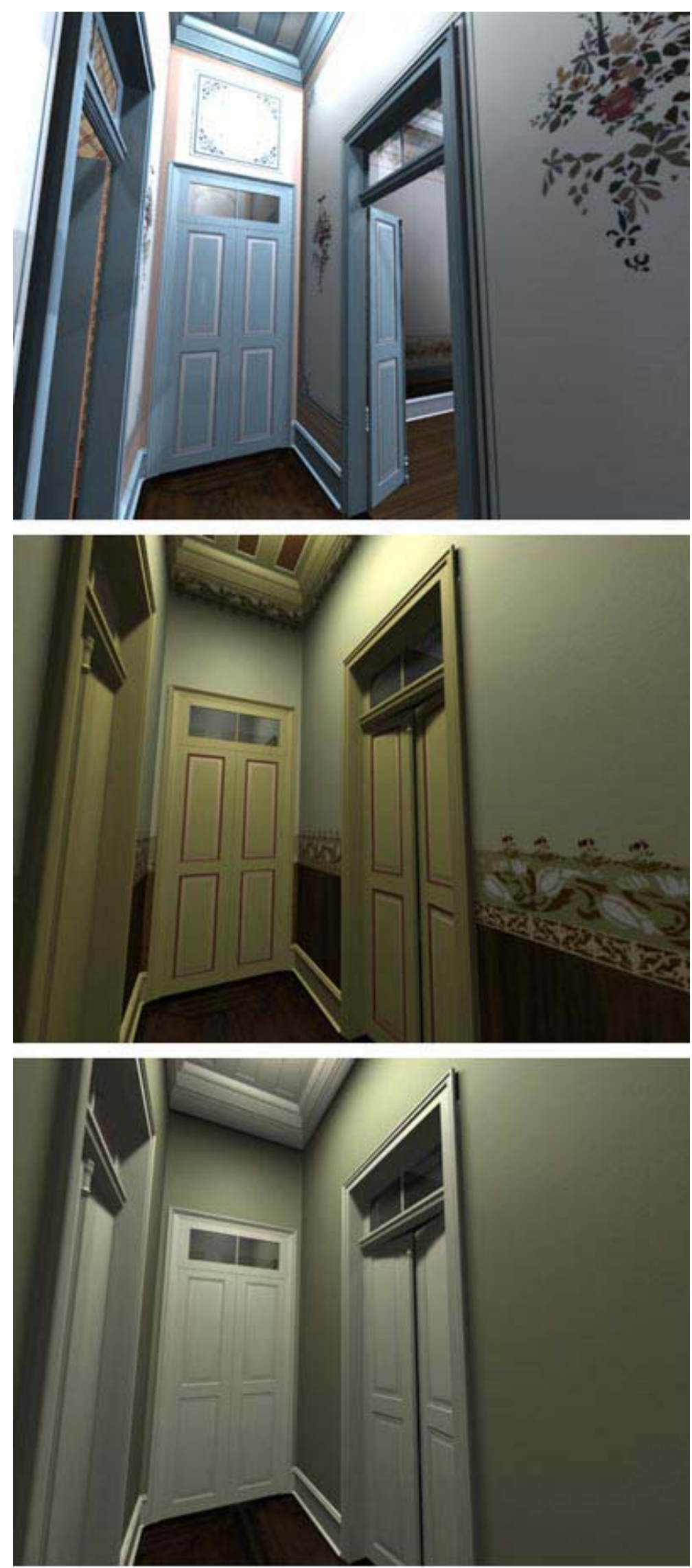

FIGURA 07 - Sinteses gráficas: Reconstituição virtual do segundo, terceiro e

quarto cidos ornamentais da casa representados no Corredor 1. Desenho: Pedro Alasmar, 2005. Fonte: Arquivo CPC-USP. 

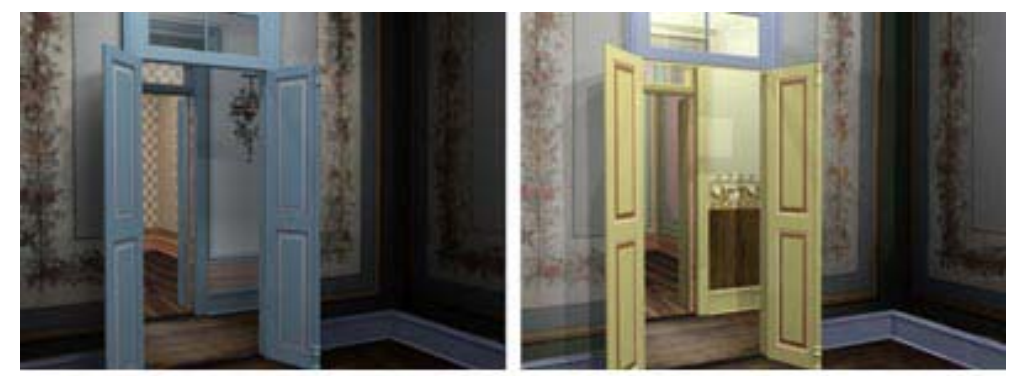

FIGURA 08 - Sinteses gráficas: Reconstituição virtual das ambiências arquitetônicas a partir da atual "Sala Azul", já restaurada pelo "Canteiro de Restauro" do CPC em 2002. (1) Simulação do primeiro periodo ornamental do Corredor 1 e Sala 06. (2) Simulação do segundo periodo ornamental do Corredor 1 e Sala 06. Desenho:

Pedro Alasmar, 2005. Fonte: Arquivo CPC-USP.

A síntese estratigráfica resultante do modelo tridimensional formulado, além de registrar as ocorrências históricas do edifício em perspectivas cientificas, presta-se à educação patrimonial.

Como resultado do desenvolvimento e implantação desse sistema de software - que possibilitará ao público leitura histórica organizada da complexa estratigrafia temporal da Casa de Dona Yayá -, objetiva-se maior difusão cultural e acesso publico aos estudos relativos às técnicas construtivas, programas habitacionais e repertório decorativo, já realizados pelo programa "Conservação e Restauro de Bens Arquitetônicos e Integrados", ampliando-se os saberes sobre as formas de construir e ornamentar residências burguesas da cidade de São Paulo, edificadas no final do século XIX, e inicio do século XX.

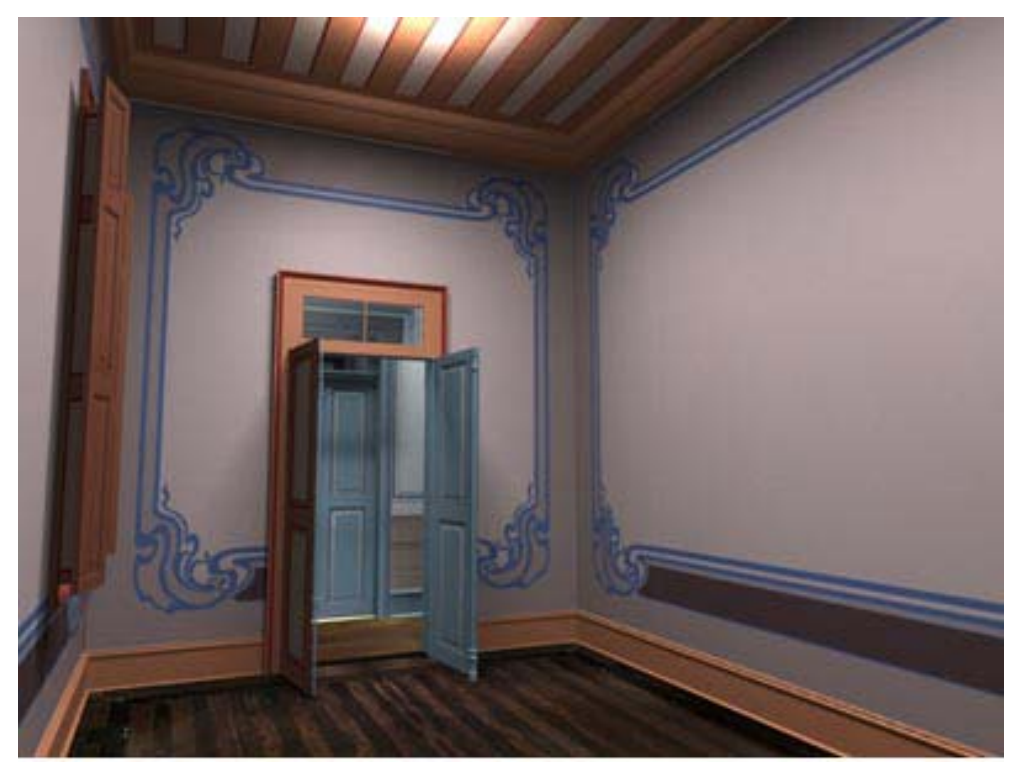

FIGURA 09 - Sinteses gráficas: Reconstituiçăo virtual das ambiências

arquitetônicas da Sala 01, em estudo para planejamento do restauro. Desenho: Pedro Murilo, 2006. Fonte: Arquivo CPC-USP. 


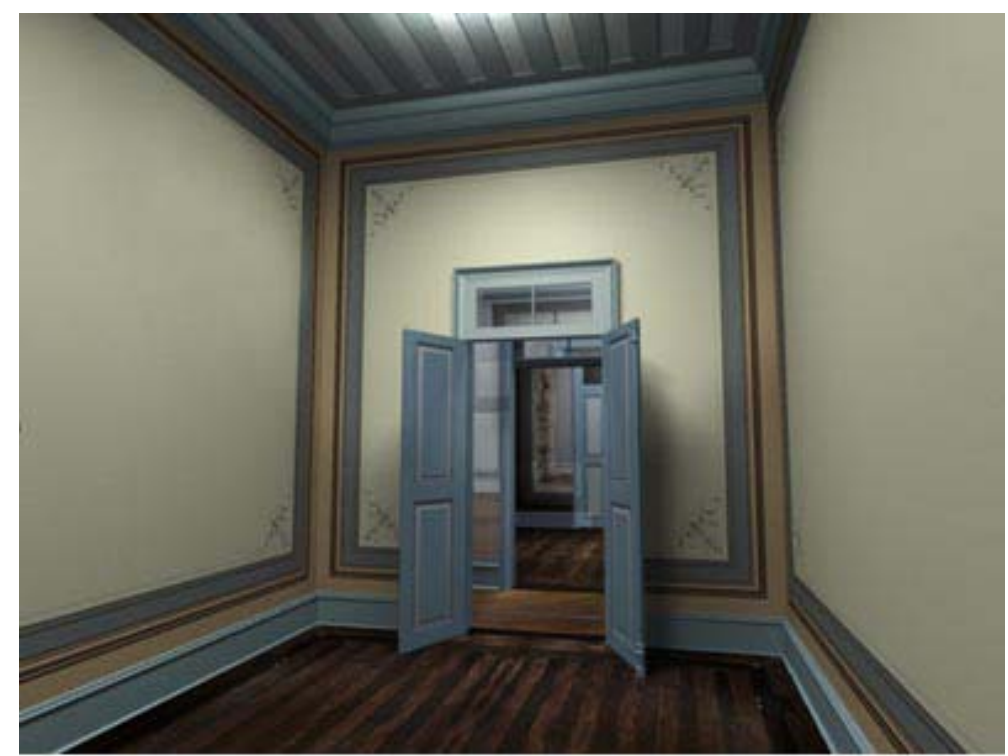

FIGURA 10 - Sinteses gráficas: Reconstituição virtual das ambiências arquitetônicas da Sala 08 , em estudo para planejamento do restauro. Ao fundo, a atual "Sala Azul", já restaurada pelo "Canteiro de Restauro" do CPC. Desenho: Pedro Murilo, 2006. Fonte: Arquivo CPC-USP.

\section{Notas}

(1) Criado em 1989, e chamado inicialmente de "Canteiro Escola de Restauração do CPC", o atual programa "Conservação e Restauração dos Bens Arquitetônicos e Integrados" mantém suas linhas diretoras principais: 1. Promover a formação qualificada em conservação e restauro de bens integrados e murais por meio de estágios de longa duração para estudantes universitários, com subprograma "Canteiro Escola de Restauro"; 2. Propor, realizar pesquisas, produzir e desenvolver sistemas de diagnóstico, registro e procedimentos operacionais de conservação arquitetônica. O programa está disponível no site www.usp.br/cpc.

(2) Além dos imóveis da Universidade de São Paulo, onde essas pesquisas se desenvolveram (Casa de Dona Yayá e Vila Penteado), destacamos outros edifícios estudados à luz deste método em São Paulo: a "Casa Modernista da Rua Santa Cruz"; o "Cine-Teatro Paramount" (atual Teatro Abril); a "Igreja da Luz"; a "Igreja do Menino Jesus e Santa Luzia", entre tantos outros. Em Campinas, o "Palácio dos Azulejos" e "Estação Guanabara". Os estudos dessa última foram iniciados com alunos da disciplina "Técnicas Retrospectivas em Arquitetura" no Departamento de Arquitetura e Construção da Faculdade de Arquitetura e Urbanismo da Unicamp (DAC/FEC-Unicamp), em 2004.

\section{Referências Bibliográficas}

ARGAN, Giulio Carlo. Historia da arte como história da cidade. São Paulo: Martins Fontes,1995.

BISCONTIN, G.; VASSALO E. Scienza e Beni Culturali: Il cantiere della conoscenza, il cantiere di restauro. Padova: Libreria Progetto Editore, 1989. 
CENTRO de Preservação Cultural da Universidade de São Paulo (CPC-USP). A Casa de Dona Yayá: [Dossiê, vencedor do Premio "Rodrigo Mello Franco" do Instituto de Patrimônio Histórico e Artístico Nacional (IPHAN)]. São Paulo: CPC-USP, 2004. Disponível em: <http://www.usp.br/cpc >

PIEROTTI P.; QUIRÓS CASTILLO J. A. Archeologia dell'architettura e storia dell'architettura: due discipline a confronto. In: CONGRESSO NAZIONALE DI ARCHEOLOGIA MEDIEVALE, 2, 2000, Firenze. [S.I.], [s.d.]. p. 377380.

TIRELLO R. A. Um trabalho arqueológico: a descoberta dos murais artísticos e a estratificação arquitetônica de uma velha casa no Bexiga. In: COMISSÃO de Patrimônio Cultural da USP. A Casa de Dona Yayá. 2. ed. São Paulo: Edusp; IMESP, 2001. p. 100-135.

O restauro dos murais art nouveau da Vila Penteado e o Canteiro-Escola da CPC-USP: uma experiência de formação qualificada. Revista Pós (FAUUSP). Vila Penteado: 100 anos. São Paulo: FAU-USP, edição especial, 2002.

Sistemas de documentación para registro de lecturas estratigráficas de edificios históricos. In: CONGRESO ARGENTINO DE ARQUEOMETRIA, 1, 2005, Rosario. Rosario: Universidad Nacional de Rosario. Adrián Pifferetti e Raúl E. Bolmaro (Org.), 2005. v. 1. (Texto completo no prelo).

Análise de cronologias construtivas: uma proposição de método de natureza arqueométrica. In: SIMPÓSIO DE TÉCNICAS AVANÇADAS EM CONSERVAÇÃO E RESTAURO DE BENS CULTURAIS, 3. , 2006, Olinda. Anais. Olinda: AERPA, 2006. CD-ROM. (cópia impressa, p.107).

Registro do patrimônio arquitetônico com tecnologia multimídia: uma possibilidade de estudo crítico e restauro eletrônico de bens culturais. In: EREG 2006 - ENCONTRO REGIONAL DE EXPRESSÃO GRÁFICA, 5., 2006, Salvador. Anais. Salvador: EREG, 2006. CD-ROM (em preparação).

*Arquiteta. Doutora pela FAU-USP. Especialista em conservação e restauro do Centro de Preservação Cultural da USP e docente do Departamento de Arquitetura e Construção da Faculdade de Engenharia Civil da Unicamp. 